\title{
On the Subject of Objects: Four Views on Object Perception and Tool Use
}

\author{
Tarja Susi / Tom Ziemke
}

School of Humanities and Informatics, University of Skövde, Sweden

Corresponding author: Tarja Susi, tarja.susi@his. se

\begin{abstract}
This paper addresses the relation between an agent and its environment, and more specifically, how subjects perceive object/artefacts/tools and their (possible) use. Four different conceptions of the relation between subject and object are compared here: functional tone (von Uexküll), equipment (Heidegger), affordance (Gibson), and entry point (Kirsh). even as these concepts have developed within different disciplines (theoretical biology, philosophy, psychology, and cognitive science) and in very different historical contexts, they are used more or less interchangeably in much of the literature, and typically conflated under the label of 'affordance'. However, at
\end{abstract}

closer inspection, they turn out to have not only similarities, but also substantial differences, which are identified and discussed here. Given that the relation between subjects and their objects is crucial to understanding human cognition and interaction with tools and technology, as well as robots' interaction with their environment, we argue that these differences deserve some more attention than they have received so far.

Keywords: functional tone, equipment, affordance, entry point, object, tool use.

\section{Introduction}

This paper takes an in-depth look at the interaction between an agent and its environment, or the relation between subject and object. More specifically, the questions addressed are how physical objects in our surroundings, and their possible uses, are perceived - what it is that makes something an object in the first place and what makes us perceive it as a tool with a certain functionality. The latter seems to be quite of interest, at least, for human cognition. Prem (1997), for example, following Heidegger, has pointed out that usually "[t]he world presents itself in the equipmental nexus", that is, we perceive the world and objects in it in terms of their possible uses. Whether indeed the world "presents itself" that way, or if we attribute it with that functionality is one of the questions addressed in this paper.

Although the subject-object, or agent-environment, relationship is one ot the oldest issues in philosophy and science, it has re-appeared recently in discussion of, for instance, "distributed cognition" (Hutchins 1995), or the "extended mind" (Clark \& Chalmers 1998). The discussions concern whether or not cognition is confined to the individual's head, or, as some argue, it is distributed over agent and environment through the use of environmental resources, which extends the bounds of cognition (e.g., Adams \& Aizawa 2001; Clark 1997, 2003; Clark \& Chalmers 1998; Hutchins 1995; Susi et al. 2003; Wilson 2004). The issue is also highly relevant, firstly, for the design of artefacts and tools for human use, in terms of considering what the properties are that make objects and their functionality easily accessible to human subjects. Secondly, it is an important issue for the question of how artificial subjects, like robots, meaningfully can perceive their environment.

This paper will have a closer look at some of the theories on the relation between subject and object, or what has been proposed under the labels of functional tone (von Uexküll), equipment (Heidegger), affordance (Gibson), and, more recently, entry point (Kirsh). The kinds of objects that are in focus here are primarily artefacts and tools. These terms have so far been elusive as far as coherent or unified definitions 
are concerned, partly due to differing perspectives and foci among researchers, and issues such as context dependency (for some definitions and viewpoints on this issue, see, e.g., Bloom 1996; Gelman \& Bloom 2000; Ingold 1993, 2000; Kemler Nelson et al. 2000; Mantovani 1996; Mitcham 1994; Pick 1997; Preston 1998; Smitsman 1997). Another reason behind the diffuculty of defining 'artefact' and 'tool' is, in our opinion, that most often attempts at defining them and their use, have been either object-centered (i.e., an object is defined according to some intended function or some properties of the object itself), or human-centered (i.e., a tool is defined as a hand-held device or something that is attached to the body). This paper does not provide any definitions of artefact or tool, since that is not the aim. Instead we focus on the subject-object relationship as a starting point. Therefore, artefact and tool here simply refer to physical objects in general and are, in accordance with much of the literature, used somewhat interchangeably ${ }^{1}$. That means, the approach taken here to understanding artefacts and their use is to take a closer look at the fundamental relation between subject and object and the way we 'objectify' (or 'toolify') things in our surroundings. A closer look at the four abovementioned theories reveals that, even though they concern the same basic phenomenon, they differ quite substantially in some aspects and provide different perspectives on the issue. In some cases they might complement each other, and in other cases there are clearly contradictions. Further motivation for attending these differences also comes from the fact that the different conceptions are commonly used quite interchangeably and are usually conflated under the label of 'affordances'. The concept of affordances as such has come to play a significant role not least in human-computer interaction (e.g., Norman 1999; Torenvliet 2003; Hartson 2003), where also the entry point concept is used, and in recent discussions of situated and embodied cognition (e.g., Clancey 1997; Clark 1997, 2003; Varela et al. 1991), and artificial intelligence robotics (e.g., Duchon et al. 1998; Effken \& Shaw 1992; Murphy 1999; Preem 1997; Stoytchev to appear).

It should be noted that the theories considered in this paper are not given an extensive account. Instead the presentation is limited to consider the aforementioned four concepts, and for comparative purposes they are viewed from a tool use perspective. The concepts are briefly described in Sections 2-5, roughly in historical order, followed by a discussion concerning their similarities and differences. The final section draws some conclusions concerning subject-object interaction and identifies a number of open research issues.

\section{Functional tone}

Jakob von Uexküll (1864-1944), a German biologist strongly inspired by the Kantian insight that all knowledge is determined by the knower's subjective ways of perceiving and conceiving, considered it the task of biology to expand Kant's research by investigating the role of the body in determining the relationship between subjects and their objects (von Uexküll 1928; cf. Ziemke 2001; Ziemke \& Sharkey 2001). A central point in his work is the idea that each animal ascribes meaning to the physical objects it encounters, and thereby fits the world to itself, constructing its own subjective universe, or Umwelt. The Umwelt is a closed unit consisting of the subject's perceptual world (Merkwelt, everything that the subject perceives) and his effector world (Wirkwelt, everything it does). But how do we come to see what things are for, for instance, that a chair is for sitting, or that a cup is for drinking? In the closed unit of subjectobject interaction, the objects acquire what von Uexküll $(1957,1982)$ termed functional tone. An example that illustrates the idea is von Uexküll's description of a man who had not previously encountered a ladder. When asked to climb the ladder the man wondered how he was supposed to do that as he saw nothing but rods and holes. The rods and holes were his receptor image. When the man was shown how to climb the ladder, he perceived the "rods and holes" as a ladder. What took place was that "the receptor image of rods and wholes had been supplemented by the effector image of his own action; through this it had acquired a new meaning. The new meaning manifested itself as a new attribute, as a functional or effector tone" (von Uexküll 1992: 358). Thus subject and object are tied to each other through several functional

\footnotetext{
${ }^{1}$ Other things, such as language or social norms, may also count as artefacts or tools. However, defining what should or should not count as an artefact is besides the present issue.
} 
circles through which an object is connected to the subject (von Uexküll 1928; 1982; 1992). Von Uexküll viewed such functional circles also as meaning circles "whose task lies in the utilization of the meaningcarriers" (1982: 36). Initially, an object may be neutral (as in the above case with the ladder), but

"...it is transformed into a meaning-carrier as soon as it enters into a relationship with a subject... Through every relationship the neutral object is transformed into a meaning-carrier, the meaning of which is imprinted upon it by a subject" (von Uexküll 1982: 27-28).

Von Uexküll further considered that objects are "always transformed into perceptual cues or perceptual images and invested with a functional tone. This alone makes them into real objects, although no element of the functional tone is actually present in the stimuli" (1957: 67). Furthermore, "everything is altered and reshaped until it becomes a useful meaning-carrier; otherwise it is totally neglected" (1982: 31). Once a relationship has been formed, objects may assume different qualities, as in the example of a stone: lying on a road, the stone provides support for walking, and as such it has acquired a "path-quality". However, if the stone is picked up and thrown at an angry barking dog, in order to chase it away, the stone is imprinted with the meaning "missile" and thus acquires quite a different quality, namely a "throw-quality". Despite the change in quality, the change does not depend on some properties of the object itself, since its properties have not changed. Actually, in von Uexküll's view, there are no properties of an object that tell us what the object is, since "all the properties of objects are actually nothing more than perceptual cues that are imprinted on them by the subject with which they enter into a relationship" (1982: 74). Instead, underlying different imprintings is the subject's prevailing mood (von Uexküll 1982). Von Uexküll used the findings from studies on hermit crabs as an example. For the crab, an "object" such as a sea anemone changes its meaning depending on the crab's prevailing mood, as seen when the crab is presented a sea anemone under three different conditions: a) the actinians the crab carries on its shell, for protection, have been removed, b) the entire shell has been removed, and c) the crab had a shell and actinians, but had been left without food for some time. Now, depending on the subject's mood, the receptor image of the sea anemone assumes different "tones" in the crab's world. With its camouflage (the actinians on the shell) removed, the anemone assumes a "defense tone", which shows through the crab's act of placing the anemone on its shell. In the case where the crab's shell has been removed, the sea anemone instead assumes a "dwelling tone", and the crab tries (unsuccesfully) to crawl into it. If the crab has not been fed for some time the anemone instead assumes a "feeding tone" and the crab starts eating it. Thus, von Uexküll pointed out that "[i]f an object is used in different ways, it may possess several effector images, which then lend different tones to the same perceptual image". Thus a chair, for instance, may assume a "sitting tone", or it may occasionally be used as a weapon since it is the subject's mood that "determines which functional image will lend its tone to the perceptual image" (1992: 358).

In sum, according to von Uexküll, each subject lives in its own subjective universe, in which subject and object form a closed unit. Initially objects are neutral, but as a subject enters into a relationship with an object, the latter becomes meaningful. Subjects imprint meaning upon the objects and transform them into meaning-carriers. As an object becomes a meaning-carrier it assumes a certain functional tone. Which functional tone it assumes depends on the subject's prevailing mood and, consequently, one and the same object may acquire different meanings in different Umwelts.

\section{Equipment}

The concept of equipment was developed by the German philosopher Martin Heidegger (1889-1976). His work has some fundamental overlaps with that of von Uexküll, but his main concern was humans rather than animals, and he paid much attention to the individual's social and cultural embedding. To begin with, Heidegger strongly opposes the traditional Cartesian subject/object distinction, and the idea of there being something mental (intentional, representational, etc.) constituting the relation between subject and object. In Dreyfus (1991: 61) words, "the stand Dasein takes on itself, its existence, is not some inner thought or experience; it is the way Dasein acts...Dasein takes a stand on itself through its involvement 
with things and people". Heidegger turned his attention beyond the mere subject-object relation, and sought to explain what it means for something to be, or to exist. In his view, the subject-object relation can only be understood in terms of being-in-the-world. The basic form of being, and " $t$ t]o exist then means, among other things, relating to oneself by being with beings" (Dreyfus 1991: 61). Being is divided into two basic ways, namely being-human (Dasein) (which is concerned with being, and is not to be taken as an entity), and non-human being. Non-human being in turn, is divided into Zuhandenheit and Vorhandenheit, usually translated into "readiness-at-hand" and "presence-at-hand". According to Dreyfus (1991), however, the meaning of these terms is better conveyed by the terms availableness and occurrentness (further discussed below).

Non-human beings, or things (Zeug), that we encounter ${ }^{2}$ in our everyday activities, including tools, materials, etc., are termed equipment or useful things:

"We shall call those entities which we encounter in concern 'equipment'. In our dealings we come across equipment for writing, sewing, working, transportation, measurement. The kind of being which equipment possesses must be exhibited" (Heidegger, 1927/1962: 97).

"We shall call the beings encountered in taking care useful things. In association we find things for writing, things for sewing, things for working, driving, measuring. We must elucidate the kind of being of useful things" (Heidegger, 1927/1996: 64).

A basic feature of equipment, or a useful thing, is that it is used in order to get something done.

"A useful thing is essentially 'something-in-order-to...'. The different kinds of 'in order to' such as serviceability, helpfulness, usability, handiness, constitute a totality of useful things. The structure of 'in order to' contains a reference of something to something" (Heidegger, 1927/1996: 64).

The reference of something to something tells us that there is nothing like an equipment, or a useful thing. Instead "useful things always are in terms of their belonging to other useful things" (Heidegger 1927/1996: 64), and there is always a totality of things, an equipmental whole, in which a thing is what it is. In the equipmental whole things are defined in terms of their different functions, but in order for an object to actually function, it must fit into the context of meaningful activity. This fitting (Bewandtnis) of an object into a wider context is termed involvement (Heidegger 1927/1962), or relevance (Dreyfus 1991; Heidegger 1927/1996), meaning that objects have an involvement with other objects. For instance:

"...the thing at hand which we call a hammer has to do with hammering, the hammering has to do with fastening something, fastening something has to do with protection against bad weather. This protection 'is' for the sake of providing shelter for Da-sein, that is, for the sake of a possibility of its being. Which relevance things at hand have is prefigured in terms of the total relevance" (Heidegger, 1927/1996: 78).

Thus anything that we use has multiple references to other tools and purposes, and "[t]he world presents itself in the equipmental nexus, in the reference to a previously seen whole" (Preem 1997: 11). The involvement of things implies that they may be chained, as in the above quote, and chained assignments end with equipment that performs just a function, and they also end with the specific user for whom the function is performed. "The last basic assignment" any piece of equipment has is to the material "where-of" it has been made, which can be produced or natural products. Thus, even raw materials may become equipment as they are brought into a context of use (Preston 1998). The concept of involvement reveals the close interconnection between subject and object. As explained by Dreyfus (1991), there is really no distinguishable subject and object, even though we might try to consider an "objective" and a

\footnotetext{
${ }^{2}$ Dreyfus (1991) points out that the standard translation (by Macquarrie \& Robinson 1962) terms "to encounter" (Begegnen) as humans encountering things, but in Heidegger's use of the term it is the other way around - things encounter us, or show up for us.
} 
"subjective" side of the referential whole, but the bottom line is that "the involvement whole and Dasein's life are both organized by the same for-the-sake-of-whichs":

"On the one hand, Dasein needs the referential whole and the involvement whole to be itself. On the other hand, the 'objective' or equipment side is organized in terms of for-the-sake-ofwhichs that are ways of being Dasein. The referential whole only makes sense because it all 'hangs,' so to speak, from for-the-sake-of-whichs that are Dasein's ways of taking a stand on itself, and Dasein exists and makes sense only because it takes over the for-the-sake-of-whichs that are built into and organize the involvement whole" (Dreyfus 1991: 98).

As mentioned above, things are what they are on the basis of their usefulness or functionality, which makes functionality a defining characteristic of equipment. However, even though objects generally are perceived in terms of their functions, their function is not determined by some perceived "objective" or context-free features, because (visual) perception per se is not the mode of access to study functioning (Dreyfus 1991). Rather, equipment is what it is only when it is actually taken up and used.

"The less we just stare at the thing called hammer, the more actively we use it, the more original our relation to it becomes and the more undisguisedly it is encountered as what it is, as a useful thing. The act of hammering itself discovers the specific 'handiness' of the hammer. We shall call the useful thing's kind of being in which it reveals itself by itself handiness. It is only because useful things have this 'being-in-themselves,' and do not merely occur, that they are handy in the broadest sense and are at our disposal. No matter how keenly we just look at the 'outward appearance' of things constituted in one way or another, we cannot discover handiness" (Heidegger, 1927/1996: 65).

Finding out the function of an object then, is connected to its use, and to the manipulation of it, which reveals what the object is and its possible use. That in turn might imply that functions can only be understood through actual manipulation, but in Heidegger's view, actual use of equipment gives rise to primordial (first-hand) understanding of it. At the same time though, equipment also has public characteristics, it is what it is regardless of who the user is, it is for a general user. Knowledge of the normal functions of equipment gives us a positive (second-hand) understanding of it (Dreyfus 1991). Thus, even though the functioning of a piece of equipment becomes available through manipulation, our understanding of equipment also depends on social norms and conventions for how things are normally used. The point of emphasising manipulation is that "theoretical knowledge depends on practical skills", that is, the need of an embodied subject. However, neither knowledge nor manipulation is considered more important than the other, since neither one constitutes or explains the relation between subject and object. The use of objects is also affected by how fluently their use proceeds. As long as there are no disturbances objects are available to us, and we are not aware of (or deliberately thinking about) how to use a particular object. However, when work is disturbed by something, the object becomes occurrent (Dreyfus 1991). Disturbances range from malfunction (conspicuousness) of a piece of equipment, to total break-down (obtrusiveness) when a piece of equipment is missing.

In sum, for Heidegger, there is an interdependent relation between subject and object, and they cannot be considered as separate entities. Subjects must be considered in their form of being-in-the-world, and objects cannot be defined according to some 'objective', context-free properties. Objects always have involvements with other equipment and therefore the meaning of terms such as "readiness-at-hand" or "presence-at-hand", cannot be considered in isolation. So, the way a tool, and its possible use, is perceived depends on the subject's ongoing activity. A piece of equipment has to fit into the context of an activity, since it is only within a meaningful context an object is what it is. Heidegger also emphasised the importance of manipulation, through which we come to understand an object's functionality. Functionality can also be understood in terms of positive understanding when there is no first-hand experience, that is, we generally know the customary way of how to use a thing. Heidegger further stressed that neither 
knowledge nor perception can explain the relationship between subject and object, instead we need to look beyond that distinction, i.e., what it means for a being to exist.

\section{Affordance}

The concept of affordance is found in the American psychologist James J. Gibson's (1904-1979) ecological psychology. As a starting point, Gibson, like Heidegger, did not agree with the traditional psychological dichotomisation between mind and body, or ideas of some psychological process operating upon incoming bodily sensations. Instead, perception is direct with no intermediary processes. In Gibson's view, each animal has its own niche in the environment, which is considered to consist of a set of affordances. At first, this might sound very similar to von Uexküll's theory, but Gibson 'locates' his affordances in the physical environment. The affordances of the environment are what they provide or offer an animal, or more formally "the affordance of anything is a specific combination of the properties of its substance and its surfaces taken with reference to an animal" (Gibson 1977: 67, italics in original). Affordances are neither purely objective nor purely subjective properties, instead an affordance cuts across the subject-object distinction and points to the reciprocal relationship between the animal and its environment (Gibson 1986). Thus, it can be said that "affordances are the entry point into the mutuality between an animal and its environment" (Wagman \& Carello 2001).

In Gibson's view, what we perceive of the environment is not "space", but surfaces, and the ambient light makes available information about reflecting surfaces. Subsequently, "the affordance itself is specified in ambient light" (Gibson 1986: 143). Gibson's use of "information" is quite different from the traditional meaning of "communication through a channel" (as in the view of Shannon and Weaver 1949). Instead, information (for vision) is a "a geometric concept defined over a transforming optic array, the $360^{\circ}$ solid angle of variations in ambient light intensity converging on a point of observation from all directions" (Mace 1977: 50). Hence, information is available in the optic array, that is, the pattern of light that reaches the eyes from reflecting surfaces in the environment (Ingold 2000).

What we perceive, looking at an object, is its affordances rather than its qualities. According to Gibson, qualities, such as colour, texture, or shape, can be discriminated if we are required to, but what we normally pay attention to is the "unique combination of qualities that specifies what the object affords us" (1977: 75). A flat surface, for instance, around the height of the knees, affords sitting-on, while an elongated object of moderate size and weight affords pounding-with. Gibson (1986) made a distinction between attached and detached objects, and considered tools to make a special kind of detached objects that are graspable, portable, and can be manipulated. A tool can (temporarily) be attached to the body, and extend the capacity of perceiving and acting. As a tool is attached to the body, it is

"...no longer a part of the environment of the user. But when not in use, the tool is simply a detached object of the environment, graspable and portable, to be sure, but nevertheless external to the observer. This capacity to attach something to the body suggests that the boundary between the animal and the environment is not fixed at the surface of the skin but can shift. More generally it suggests that the absolute duality of 'objective' and 'subjective' is false" (Gibson 1986: 41). ${ }^{3}$

A tool then, is not a tool just because an object is conceived of or has been labelled as such, rather tools are a special class of objects that are graspable and so on, and, importantly, extend our capacities for perceiving and acting (for a discussion on the boundary between agent-environment, see also Susi et al. 2003). The above quote also points to the problematic subject-object distinction, which ecological psychology avoids by turning its attention to affordances. As mentioned earlier, affordances are relative to

\footnotetext{
${ }^{3}$ We might note that interestingly, Gibson's claim regarding the flexible boundary has very recently been shown to be, at least partly, true in cognitive neuroscience experiments with macaque monkeys using handheld tools (Maravita \& Iriki 2004; see also e.g., Berti \& Frassinetti 2000).
} 
an animal, and as Gibson emphasises, they are "a combination of physical properties of the environment that is uniquely suited to a given animal-to his nutritive system or his action system or his locomotor system". Concerning tools, Gibson also adds that when manipulability is perceived by an observer, it is "in relation to his hands, to which the object or tool is suited" (1977: 79). A hammer, for instance, is (generally) perceived as well suited for pounding nails, fitting both the task and the hand. As the hammer is used, the user's needs may change though. Instead of pounding, the reversal action of pulling out a nail may be required, in which case the user perceives other affordances. However, contrary to von Uexküll's view of functional tone:

"The affordance of something does not change as the need of the observer changes. The observer may or may not perceive or attend to the affordance, according to his needs, but the affordance, being invariant, is always there to be perceived. An affordance is not bestowed upon an object by a need of an observer and his act of perceiving it. The object offers what it does because it is what it is" (Gibson 1986: 138-139).

Thus affordances are invariant and do not change according to the needs of the observer. Instead it is a matter of perceiving or paying attention to (or not) the existing affordances. Gibson also emphasises the role of the body in perceptual activity, and which affordances an animal perceives is related to its movements. The ambient light converges on a point of observation, but as an animal moves around its point of observation constantly changes, and so does the perceived pattern of light. Subsequently, a certain point of observation may or may not be occupied by an observer, but the affordances themselves always remain there to be perceived. While affordances are objective properties of the environment, in the sense that they are in the physical world, perceived affordances are subjective, in the sense that they depend on the context of its activity (Mace 1977). For instance, whether an animal perceives that a gap can be jumped over or not depends on whether it is standing beside the gap, or if it is running towards it. Sometimes affordances can be misperceived, that is, we may fail to perceive what is present or perceive something not present, both of which are cases of misperception (Gibson 1986). For instance, studies concerning a "visual cliff" by Gibson and Walk (1960, in Gibson 1986), showed that infants still perceived that the cliff afforded falling off, even when a sheet of glass was extended out over the edge. Likewise, we may not perceive (or misperceive) a closed door that is made of glass, and therefore walk right into it.

In addition to perceived affordances of objects, and similar to Heidegger's point of second-hand knowledge of functionality, Gibson pointed out that our use of objects is affected by social norms and experiences, and knowledge of conventional ways to use an object. For instance, above a certain age everyone knows what a mailbox is for. Furthermore, at the social level there is an enormous complexity of affordances and, in Gibson's view, the richest and most elaborate affordances for humans are provided by other people.

In sum, Gibson opposes the subject-object dichotomisation and instead emphasises the reciprocal relationship between subject and object, where each subject lives in its own niche, or set of affordances. Information about the environment, its affordances, is made available in the perceived patterns of light that are reflected from surfaces. Hence, affordances are objective properties in the environment, objective in the sense that they are invariant and always there to be perceived. Even though a user's needs may change, the affordances do not. However, affordances are always in relation to the subject, and the subject's bodily movement is crucial for the perceptual activity.

\section{$5 \quad$ Entry point}

In cognitive science and human-computer interaction research, some concepts that are comparable to the ones described above, have appeared in the work of David Kirsh. This emerging theoretical work is an effort to understand and improve representations of work contexts. Central concepts in this approach are entry points, cognitive affordances, and cognitive congeniality (Kirsh 1995b; 2001). Cognitive congeniality 
refers to the cognitive hospitability of an environment. In Kirsh's view, interactions with the environment can be made more efficient through active restructuring of the environment, that is, an increase of the environment's hospitability. When discussing environments, Kirsh mainly refers work places like offices. There are many different ways of improving performance in such task environments, and in Kirsh's (1995b; 1996) view, sometimes the best way to solve a cognitive problem is to adapt the world instead of adapting oneself. That way people can reduce mental computational efforts, and improve their performance.

Kirsh (1996) identifies two families of strategies for restructuring the environment. The first one is to deform the topology of the state space of a task, which can be achieved in several ways. One of the most powerful ways is through tool use. For instance, new tools may be introduced, or existing tools may be put to a new use. The second strategy is to increase the cognitive congeniality of existing state spaces. One way of doing that is by use of complementary strategies, which are defined as "any organizing activity which recruits external elements to reduce cognitive loads" (Kirsh 1995a: 212; cf. Clark 1997). Such external elements could basically be anything that encodes the state of a process or that simplifies perception, for instance, fingers or hands, pen and paper, measuring devices, or other "entities" in our immediate environment. Hands, for instance, may be used as a complementary strategy when counting coins (Kirsh 1995a). By pointing, a person can keep track of the coins already counted, thereby off-loading his cognitive processes, and perform the task in a more efficient way. Complementary strategies, then, help to save mental effort through alterations of the cognitive properties of people's environments. The prime purpose of such strategies is not to make it easier to accomplish a task in terms of reaching a goal. Rather they are undertaken because they affect the way a task is understood, and because they create cognitive affordances, thereby off-loading cognitive demands (Kirsh 1996).

Closely related to cognitive affordance, is the entry point concept. Entry points are used as a way of achieving cognitive affordances. As Kirsh (2001) points out, entry points are much like affordances, that is, they invite us to do something, "typically information or communication related things". In other words, an entry point is "a structure or cue that represents an invitation to enter an information space or office task" (2001: 305). Such cues in offices are, for instance, piles of paper, folders, day planners, notes, and lists of things to do. What people do is that they create collections of entry points that tell them what is going on, what needs to be done during the day, what needs to be taken care of the next day, and so on. As preferences for the number and type of entry points differ, such entry point collections are personal. Some office occupants, "neats", keep their desks tidy with, for instance, a few well-organised piles of paper or folders on their desks, which provides a clear structure with a controlled amount of entry points. Neats also stabilise their environments at the end of the day, leaving few entry points that can attract them in the morning. "Scruffies", on the other hand, are (or at least seem to be) less in control. Their desks are filled with piles of paper, folders, notes, post-its, reminders, and all kinds of things found in an office. Scruffies also make use of ad hoc categories to a greater extent, that is, they create categories as needed. Either way, with a high or a low degree of structure, the structure provides external scaffolding for their work tasks.

The entry points created by office occupants have different properties, or characteristics, that affect the way people react to them, properties that vary along a number of key dimensions (Kirsh 2001):

- Intrusiveness: how much attention, visually or sensorially, an entry point attracts. For instance, items with different colours, or shape and quality of papers and files, attract different amounts of attention. Intrusiveness determines the probability that the entry point will be approached.

- Richness in metadata: how much the entry point tells about its underlying information. Headings, pictures, markings, etc., all provide information about what the entry point holds. The more metadata the entry point holds, the less needs to be kept in memory. 
- Visibility: how distinct or unobstructed the entry point is. Some entry points, like calendars, to-do lists, or a pile on the desk are more visible than others, like folders in a filing cabinet. The higher the visibility of the entry point, the higher the chance it will be used.

- Freshness: when was the entry point last touched? Recency influences recall, and recently touched files, papers, notes, etc., are more likely to be used in current activity.

- Importance: how pressing the activity, associated with the entry point, is. An upcoming due date, e.g., increases the importance of a matter.

- Relevance: how useful an entry point is to current activity. The probability of using a certain entry point increases the more relevant the entry point is.

While the first four dimensions are considered objective, that is, they are user independent, the last two are subjective, that is, relative to a user.

In sum, Kirsh's theoretical work takes an interest in how active subjects make use of environmental structures to achieve various tasks, focusing specifically on work contexts, such as offices. Emphasis lies on the co-adaptation of agent and environment (or office occupant and office). People actively structure their environments, and create sets of entry points, which scaffold their daily work. The structure provided by entry points reduces cognitive demands and help people to improve their performance. Entry points are environmental structures that invite people to enter an information space or office task, and they may be objective (user independent) or subjective (user dependent). This emerging theoretical work is influenced by Gibsonian psychology, and as Kirsh admits, entry points are much alike affordances as they are both invitations to do things.

\section{Discussion}

Having briefly described these different views on the relation between subject and object, we now move to a comparative discussion. At a first glance these different perspectives have clear similarities, but at a closer look they also turn out to have significant differences.

Common to the first three views of von Uexküll, Heidegger, and Gibson is that they seek to avoid a dualistic view of subject and object as two distinct entities. Both von Uexküll and Gibson emphasise the reciprocal relationship between an animal and its environment. In von Uexküll's view each animal lives in its own niche, or subjective Umwelt, and Gibson considers each animal has having its own niche, consisting of a set of affordances. In Heidegger's view, subject and object cannot be viewed as two separate entities as they are strongly interdependent, both of them meaningful only within a referential whole. Heidegger also strongly opposes the idea of some kind of mental mediation (intentionality, representations, etc.) between subject and object. Likewise, in Gibson's view, there are no intermediary links between subject and object, in this case some psychological process between perception and cognition. Instead, Gibsonian ecological psychology considers perception as direct (however, see also Costall 1989). While these first three views discuss, and avoid, a subject-object distinction, Kirsh does not directly address the issue of subject-object dichotomisation. However, considering that entry points are discussed in relation to office occupants (or understanding work context), it might be taken to imply a mutuality between subject and object. Each office occupant uses various objects to create her own entry points, which then are in relation to that specific person. The entry points can also be seen by others (assuming people enter others' offices and that the entry points are visible), but they would not necessarily have the same meaning for them as for the person who created them. In that case, there is a mutuality between an office occupant and her "niche", the office. On the other hand, considering that some entry points are objective, or user independent, it might imply that an entry point is not necessarily related to the person who created it, but that it is a general entry point for a general observer.

Another similarity between von Uexküll and Gibson is the distinction between the physical environment and the perceptual world. However, there is a crucial difference in where they consider information to be 
'located'. In von Uexküll's view, objects are meaningless entities as objects in themselves do not have any properties, and as such they are discarded by an animal. However, as an animal enters into a relationship with an object it ascribes some meaning to the object, which then becomes a meaningful entity that assumes a functional tone. Which functional tone it assumes depends on the subject's needs or prevailing mood. Through such relationships the animal forms its own subjective universe. In Gibson's view, on the other hand, an animal's perceived environment consists of a set of affordances. The affordances themselves are objective properties found in the environment, and they are specified in the ambient light. Thus information is 'located' in the environment. In contrast to functional tone, affordances are invariant, always there to be perceived and objects do not "assume" affordances, nor are affordances bestowed upon objects according to an observer's needs. As for entry points, they might be taken as properties found in the environment, considering the similarity between affordances and entry points. However, while an affordance is considered as "the entry point into the mutuality between an animal and its environment", Kirsh seems to (more or less) equate entry points with affordances. It is not clear in what way Kirsh distinguishes entry points from affordances, or why the term entry point is chosen for what seems to be affordances (in Gibsons terms). In the case of cognitive affordances, they may be considered as a subclass of affordances. From an ecological perspective, with focus on explaining perception, affordances encompass a wider spectrum of environmental information than does cognitive affordances, which instead are limited to information related to cognitive processes. Kirsh deviates from an ecological view on affordances in that entry points are characterised along six dimensions, of which some are "objective", or user independent (intrusiveness, metadata rich, visibility, freshness), while others are "subjective", or user dependent (importance, relevance). As office occupants and their offices co-adapt, and workers actively structure their environments by creating structure through sets of entry points, the entry points are directly related to an active agent, rather than any agent(s), as implied by "objective". From an ecological perspective, entry points would be objective in the sense that they are found in the environment, inviting us to take action. However, considering the "objective" dimension of, for example, freshness, it is not clear in what way it is objective. The time elapsed since an item has been touched does not seem as an objective property of the item itself (unless a visible marking, like a date, has been added to it). The time of use of an object is directly related to the person who has used the object, not to other users, and freshness is then only meaningful to that specific person (unless one deals with cooperative processes, which is not the case in Kirsh work). Considering that entry points are related to the work context of an office occupant, all entry points could be seen as user dependent.

The four perspectives differ in their view on the body's role in the relation between subject and object. In Heidegger's work the role of the body is perhaps most apparent in the emphasis on object manipulation, through which a subject gains first-hand understanding of what an object is for. From Gibson's ecological perspective affordances are always perceived from a certain point of observation. The subject's point of observation changes as it moves around, and, hence affordances are related to the subject's bodily movements. In von Uexküll's work the body firstly determines what the organism can sense, and thus its perceptual world. Furthermore, the subject's prevailing mood, presumably strongly dependent on the bodily state, determines the functional tone of an object. For instance, in the case of hunger in a crab, a sea anemone may assume a feeding tone. Likewise, a rock, large enough to sit on, may assume a sitting tone if a person needs to rest her feet, but if the subject aims at throwing something at a barking dog the same rock does not assume a throwing tone because it is too heavy for throwing. In the case of entry points, the body's role in the relationship between subject and object is not directly addressed, perhaps due to a somewhat different level of abstraction, focusing to a larger extent on cognitive aspects, and ways to reduce cognitive demands.

Another difference in the four views concerns the matter of context dependence. Heidegger considers equipment as meaningful only within the context of its use, through which an object is what it is. The functional tone of an object is also context dependent, as seen, for instance, in the case of a stone that can assume a path-quality or a throw-quality, depending on the subject's prevailing mood. Affordances, on 
the other hand, are context independent as they are invariant and do not change as the needs of the observer changes. Yet, at the same time, affordances may be seen as context dependent as they are taken with reference to an animal and its point of observation. Considering that animals move around, the perceived affordances constantly change and which affordances it perceives depends on what it is presently doing, as in the case of standing by or approaching a gap. In entry points we find both objective and subjective dimensions, and they seem to fall in both categories of context in-/dependence. On the one hand, objective entry points may seem as context independent as they are properties found in the environment, and whether they are perceived or not depends on how much attention they catch. On the other hand, subjective entry points seem to be context dependent, as they are directly related to the office occupant and her ongoing work tasks. However, all dimensions of entry points may be considered context dependent, since an ongoing work task may affect what the office worker looks for in the first place. Another aspect of context in-/dependence is the social and cultural practices of the agent's environment, which play some role in understanding what an object is and what it is used for. Heidegger and Gibson both emphasised that understanding objects and their use partly depends on social norms and knowledge of conventional ways of how to use an object. However, Gibson has also been criticised for treating "culture as merely a kind of potentially distorting screen partly interposed between us and an independent, 'real' world" (Costall 1989: 19). Von Uexküll, focusing on the role of the body and each animal's subjective construction of its world, did not include socio-cultural aspects of context in this niche construction. Neither does Kirsh explicitly address the role of socio- cultural practices and conventions, but they are implicitly a part of the entry point concept in that entry points, generally speaking, are made out of the artefacts used in offices, and the use of artefacts is typically embedded in, and based on cultural knowledge (e.g., of how to use a day planner or a filing cabinet).

As we have seen, the agent-environment relationship may be viewed in different ways, and how to conceptualise it is a relevant question when considering, for instance, the design of technology where users need to perceive its functionality, and in the design of artificial subjects like robots, and their possibility to perceive and actively adapt the world according to their needs. Interactive technology is a crucial element of most modern work places, and at least since Norman's (1988) introduction of affordances (and misperceived affordances) in human-computer interaction in the 1980s, there has been a common idea that users should perceive an object's functionality (desirably) by just looking at the object. While affordances, and especially cognitive affordances, have become popular and widely used, e.g., in the human-computer interaction/usability engineering community, the use of the term affordance has become confused, and lost its original meaning all together (Torenvliet 2003) ${ }^{4}$. Furthermore, phenomena that might be better explained in other terms, are often conflated under the term of 'affordance'.

Let us consider an example, not of technology, but a more 'simple' object, a specific document used in a work place where staff members handle deliveries of grain to a silo (for further details see Susi 2005). For each delivery certain documents are printed out, among them a strip of bar codes used for labelling grain samples (hereafter called 'document'). The document is placed on a desk, and the next worker who comes along takes the document and goes to take the sample. In tems of functional tone the document itself is a neutral object, but as the workers enter into a relationship with the object it becomes a useful meaning-carrier. Thus, for the worker who places the document on the desk it assumes the meaning of 'a means for labeling a sample' or 'a sample needs to be taken'. For the worker who takes all the samples, the document instead assumes the meaning 'take a sample'. In terms of equipment the way the document, and its possible use is perceived, depends on the ongoing activity in this workplace. It is only within the meaningful context of handling deliveries that the document is what it is - a useful tool for grain sampling. The usefulness of this tool also lies in the equipmental whole, the totality of things to which it belongs. In terms of affordances the document instead has objective properties that are perceived directly - properties that afford different actions. As it is placed on the desk, it may afford a number of things, such as lifting, holding, carrying, writing, etc. The entry point concept is similar to affordances in that the

\footnotetext{
${ }^{4}$ Recently, the problem of that confusion has become an issue of discussion and clarification (e.g., Norman 1999; Hartson 2003).
} 
document (as an entry point) is a cue that invites a worker to do something. The document attracts, e.g., visual attention due to its specific location on the desk (a high degree of intrusiveness), which invites taking an action. However, the affordance and entry point concepts do not explain in what way the document actually affords, or invites, the action of taking a sample. There is nothing in the object itself that affords such an action, and there is no text saying 'take a sample' (which would afford reading the symbols, but not to take a sample anyway). Nevertheless, along with the common use of the affordance concept, most people would probably agree that the document affords/invites taking the sample, or that the document has cognitive affordances that guides the worker to taking the sample. It is important, however, that we pay attention to the differences between these concepts.

In a much simplified way, we might say the following: functional tone concerns the way people ascribe certain meanings to objects from the subject's point of view; equipment relates objects to a whole chain of other objects and the context of an activity, which gives the object its meaning in the first place; affordances concern possible actions in an environment (which can be made salient or, in case of unwished actions, may be hidden); entry points describe different characteristics of objects, from a cognitive point of view, which affect the way people react to them. The point is, as said before, that phenomena that might be better explained in other terms, are often conflated under the term of 'affordances'. Consequently, the commonly used notion of 'misperceived affordances' of functionality, may also in fact be a question of technology attributed with different functional tones by different users, rather than not perceiving the supposed 'affordances' correctly. Similarly, in artificial intelligence and robotics the term affordance is commonly used to refer to some internal mechanism or construct, e.g. in phrases like "learning an affordance" or "representing an affordance", that are more compatible with von Uexküll's view of functional tones as subjective constructions than with the Gibsonian notion of affordances as directly perceived and 'located' in the environment. The case of artificial subjects' (systems') affordances also illustrates the fact that Gibson's notion of affordances as being invariant, and independent of whether they are perceived or not, is not unproblematic. If, for example, some time in the future somebody built a robot big and strong enough to grasp and lift your car, we would have to say that for such a robot your car affords grasping and lifting already today although no such robot exists yet. That means, if you take Gibson seriously on this point, the world is already now full of affordances for any number of future subjects that still have to be constructed or evolve naturally.

Finally, it might be pointed out that, for obvious reasons, Kirsh's theoretical work, a relative newcomer on the scene, falls somewhat short in a comparative discussion of the four views considered here, as it has a narrower focus and is much less elaborated than the other perspectives. Nevertheless, it can be seen as a promising approach to capturing work contexts.

\section{Conclusion}

This paper has discussed four different conceptions of the relation between an agent and its environment, and how subjects perceive objects/artefacts/tools and their possible use: von Uexküll's functional tone, Heidegger's equipment, Gibson's affordance, and Kirsh's entry point. Even though the agent-environment relationship is an old issue in philosophy and science, it has re-appeared recently in discussions of, for instance, "distributed cognition" or the "extended mind". There are open research questions in the study of subject-environment interaction, and one of the most interesting ones is not just the question of how existing objects and their functionalities are perceived, but also how humans and other animals actively structure their world such that sufficient 'cognitive scaffolding' (in the form of affordances, functional tones, entry points, or whatever your favorite term is) is available to support meaningful action sequences, rather than just individual reactions. This is of particular interest in collaborative work environments. In such environments social interactions and work coordination (distributed cognitive processes in the sense of Hutchins 1995) are often mediated by the physical environments (e.g. Susi 2005; Rambusch et al. 2004), that is, physical changes resulting from the actions of one person trigger the actions of another person, and so on. We have discussed elsewhere in more 
detail that the capacity to modify the physical environment in order to create such cognitive scaffolding for individual and distributed cognitive processes is still lacking almost completely from current artificial and robotics research (Ziemke et al. 2004). That means, while there is plenty of research on robots adapting to their environments, there is very little work on robots adapting their environments to their own needs and cognitive limitations. This is yet another indication that despite the emphasis on agent-environment interaction in much recent work on situated, embodied and distributed cognition, the question how the subject objectifies its environment, and uses it as a scaffold, is still far from being well understood. Subsequently, there is need for a more systematic understanding of these issues (cf. Clark 2002), and our own work will in the near future focus on the development of a framework concerning objects, or artefacts, and interactions. Questions of interest are, for instance, in what ways different kinds of artefacts mediate and scaffold different kinds of interactions, and what it is about artefacts that make them function as scaffolds. These issues are of importance for gaining a more thorugh understanding of artefacts and their role(s) in social interactions (Susi forthcoming).

\section{References}

Adams, Fred/Aizawa, Ken (2001) The Bounds of Cognition. In: Philosophical Psychology, 14 (1), 43-64.

Berti, Anna \& Frassinetti, Francesca (2000) When far becomes near: Remapping of space by tool use. In: Journal of Cognitive Neuroscience, 12:3, 415-420.

Bloom, Paul (1996) Intention, history, and artifact concepts. In: Cognition, 60, 1-29.

Clancey, William J. (1997) Situated cognition: On human knowledge and computer representations. Cambridge. University Press.

Clark, Andy (1997) Being there: Putting brain, body, and world together again. Cambridge, Mass. MIT Press.

Clark, Andy (2002) Towards a science of the bio-technological mind. In: International Journal of Cognition and Technology, 1(1), 2133.

Clark, Andy (2003) Natural-born cyborgs: Minds, technologies, and the future of human intelligence. Oxford. University Press.

Clark, Andy/Chalmers, David (1998) The Extended Mind. In: Analysis, 56, 10-23.

Costall, Alan (1989) A closer look at direct perception. In: Gellatly, Angus/Rogers, Don/Sloboda, John A. (Eds.) (1989) Cognition and Social Worlds. Oxford. Clarendon Press. pp. 10-21.

Dreyfus, Hubert L. (1991) Being-in-the-world. A commentary on Heidegger's Being and Time, Division 1. Cambridge, MA. The MIT Press. (sixth printing, 1995)

Duchon Andrew P./ Warren, William H./Kaelbling Leslie Pack (1998) Ecological Robotics. In: Adaptive Behavior, 6(3-4), 473-507.

Effken, Judith A./Shaw, Robert E. (1992) Ecological Perspectives on the New Artificial Intelligence. In: Ecological Psychology, 4 (4), 247-270.

Gelman, Susan A. \& Bloom, Paul (2000) Young children are sensitive to how an object was created when deciding what to name it. In: Cognition, 76, 91-103.

Gibson, James J. (1977) The theory of affordances. In: Shaw, Robert/Bransford, John (Eds.) (1977) Perceiving, Acting and Knowing: Toward an ecological psychology. Hillsdale, NJ. Lawrence Erlbaum Associates. pp. 67-82.

Gibson, James J. (1986) The ecological approach to visual perception. Hillsdale, NJ. Lawrence Erlbaum Associates. (Original work published in 1979)

Hartson, Rex (2003) Cognitive, physical, sensory, and functional affordances in interaction design. In: Behaviour \& Information Technology, 22(5), 315-338.

Heidegger, M. (1927/1962) Being and time. Translated by Macquarrie, John/Robinson, Edward. Oxford. Blackwell.

Heidegger, Martin (1927/1996) Being and Time. A translation of Sein und Zeit. Translated by Stambaugh, Joan. New York. State University of New York Press.

Hutchins, Ed (1995) Cognition in the wild. Cambridge, Mass. The MIT Press.

Ingold, Tim (1993) Tool-use, sociality and intelligence. In: Gibson, Kathleen R/Ingold, Tim (Eds.) (1993) Tools, language and cognition in human evolution. Cambridge. Cambridge University Press. pp. 429-444.

Ingold, Tim (2000) The perception of the environment: Essays in livelihood, dwelling and skill. London. Routledge.

Kemler Nelson, Deborah G./Frankenfield, Anne/Morris, Catherine/Blair, Elisabeth (2000) Young children's use of functional information to categorize artifacts: Three factors that matter. In: Cognition, 77, 133-168.

Kirsh, David (1995a) Complementary strategies: Why we use our hands when we think. In: Proceedings of the Seventeenth Annual Conference of the Cognitive Science Society. Hillsdale, NJ. Lawrence Erlbaum.

Kirsh, David (1995b) The intelligent use of space. In: Artificial Intelligence, 73, 31-38.

Kirsh, David (1996) Adapting the environment instead of oneself. In: Adaptive Behavior, 4(3/4), 415-452.

Kirsh, David (2001) The context of work. In: Human-Computer Interaction, 16, 305-322.

Mace, William M. (1977) James J. Gibson's strategy for perceiving: Ask not what's inside your head, but what your head's inside of. In: Shaw, Robert/Bransford, John (Eds.) (1977) Perceiving, acting, and knowing. Toward an ecological psychology. Hillsdale, NJ. Lawrence Erlbaum Associates. pp. 43-65. 
Mantovani, Giuseppe (1996) New communication environments: From everyday to virtual. London. Taylor \& Francis.

Maravita, Angelo \& Iriki, Atsushi (2004) Tools for the body (schema). In: TRENDS in Cognitive Science, 8(2), 79-86.

Mitcham, Carl (1994) Thinking through technology: The path between engineering and philosophy. Chicago. The University of Chicago Press.

Murphy, Robin R. (1999) Case studies of applying Gibson's ecological approach to mobile robots. In: IEEE Transactions on Systems, Man, and Cybernetics, 29(1), 105-111.

Norman, Donald (1988) The psychology of everyday things. New York. Basic Books.

Norman, Donald (1999) Affordances, conventions, and design. In: Interactions, May/June, 38-42.

Pick, Anne D. (1997) Perceptual learning, categorizing, and cognitive development. In: Dent-Read, Cathy/ Zukow-Goldring, Patricia (Eds.) (1997) Evolving explanations of development. Washington. American Psychological Association. pp. 335-370.

Prem, Erich (1997) Epistemic autonomy in models of living systems. In: Proceedings of the Fourth European Conference on Artificial Life. Cambridge, MA. MIT Press.

Preston, Beth (1998) Cognition and tool use. In: Mind \& Language, 13(4), 513-547.

Rambusch, Jana/Susi, Tarja/Ziemke, Tom (2004) Artefacts as mediators of distributed social cognition: A case study. In: Forbus, Kenneth/Gentner, Deirdre/Regier, Terry (Eds.) (2004) Proceedings of the 26th Annual Conference of the Cognitive Science Society. Mahwah, NJ: Erlbaum.

Shannon, Claude E. \& Weaver, Warren (1949) The mathematical theory of communication. Urbana. Illinois. University of Illinois Press.

Smitsman, Ad W. (1997) The development of tool use: Changing boundaries between organism and environment. In: Dent-Read, Cathy/Zukow-Goldring, Patricia (Eds.) (1997) Evolving explanations of development. Washington. American Psychological Association. pp. 301-329.

Stoytchev, Alexander (to appear) Behavior-Grounded Representation of Tool Affordances. In: Proceedings of IEEE International Conference on Robotics and Automation (ICRA). Barcelona, Spain, April 18-22, 2005.

Susi, Tarja (forthcoming) The puzzle of social activity and cognition - How tools matter (working title). Doctoral dissertation. University of Linköping. University of Skövde.

Susi, Tarja (2005) In search of the Holy Grail: Understanding artefact mediation in social interactions. In: Bara, Bruno G./Barsalou, Lawrence/Bucciarelli, Monica (Eds.) (2005) Proceedings of the $27^{\text {th }}$ Annual Conference of the Cognitive Science Society, 21102115. Mahwah, NJ: Lawrence Erlbaum.

Susi, Tarja/Lindblom, Jessica/Ziemke, Tom (2003) Beyond the bounds of cognition. In: Alterman, Richard \& Kirsh, David (Eds.) (2004) Proceedings of the $25^{\text {th }}$ Annual Conference of the Cognitive Science Society. Mahwah, NJ: Lawrence Erlbaum.

Torenvliet, Gerard (2003) We can't afford it! The devaluation of a usability term. In: Interactions, X.4, July/August, 12-17.

Varela, Francisco J./Thompson, Evan/Rosch, Eleanor (1991) The embodied mind: Cognitive science and human experience. Cambridge, MA. MIT Press.

von Uexküll, Jakob (1928) Theoretische Biologie. Berlin. Springer Verlag.

von Uexküll, Jakob (1957) A stroll through the worlds of animals and men - a picture book of invisible worlds. In: Schiller, Claire $H$. (Ed.) (1957) Instinctive Behaviour - The Development of a Modern Concept, pp. 5-80. New York. International Universities Press. Appeared also in Semiotica, (1992), 89(4), 319-39. Originally appeared as von Uexküll (1934) Streifzüge durch die Umwelten von Tieren und Menschen. Berlin. Springer.

von Uexküll, Jakob (1982) The theory of meaning. In: Semiotica, 42-1, 25-82. Originally appeared as: von Uexküll, Jakob (1940) Bedeutungslehre. Leipzig. Verlag von J.A.Barth.

Wagman, Jeffrey B. \& Carello, Claudia (2001) Affordances and inertial constraints in tool use. In: Ecological Psychology, 13(3), 173195.

Wilson, Robert A. (2004) Boundaries of the mind: The individual in the fragile sciences. Cambridge: Cambridge University Press.

Ziemke, Tom (2001) The Construction of 'reality' in the robot. In: Foundations of Science, 6(1), 163-233.

Ziemke, Tom/Sharkey, Noel (2001) A stroll through the worlds of robots and animals: Applying Jakob von Uexküll's theory of meaning to adaptive robots and artificial life. In: Semiotica, 134(1-4), 701-746.

Ziemke, Tom/Bergfeldt, Nicklas/Buason, Gunnar/Susi, Tarja/Svensson, Henrik (2004) Evolving cognitive scaffolding and environment adaptation: A new research direction for evolutionary robotics. In: Connection Science, 6(4), 339-351. 